\title{
Renin-angiotensin system activation correlates with microvascular dysfunction in a prospective cohort study of clinical sepsis
}

\author{
Kevin C Doerschug ${ }^{1 *}$, Angela S Delsing ${ }^{1}$, Gregory A Schmidt ${ }^{1}$, Alix Ashare ${ }^{2}$
}

\begin{abstract}
Introduction: Microvascular dysregulation characterized by hyporesponsive vessels and heterogeneous bloodflow is implicated in the pathogenesis of organ failure in sepsis. The renin-angiotensin system (RAS) affects the microvasculature, yet the relationships between RAS and organ injury in clinical sepsis remain unclear. We tested our hypothesis that systemic RAS mediators are associated with dysregulation of the microvasculature and with organ failure in clinical severe sepsis.

Methods: We studied 30 subjects with severe sepsis, and 10 healthy control subjects. Plasma was analyzed for plasma renin activity (PRA) and angiotensin II concentration (Ang II). Using near-infrared spectroscopy, we measured the rate of increase in the oxygen saturation of thenar microvascular hemoglobin after five minutes of induced forearm ischemia. In so doing, we assessed bulk microvascular hemoglobin influx to the tissue during reactive hyperemia. We studied all subjects 24 hours after the development of organ failure. We studied a subset of 12 subjects at an additional timepoint, eight hours after recognition of organ failure (early sepsis).

Results: After 24 hours of resuscitation to clinically-defined endpoints of preload and arterial pressure, Ang II and PRA were elevated in septic subjects and the degree of elevation correlated negatively with the rate of microvascular reoxygenation during reactive hyperemia. Early RAS mediators correlated with microvascular dysfunction. Early Ang II also correlated with the extent of organ failure realized during the first day of sepsis.

Conclusions: RAS is activated in clinical severe sepsis. Systemic RAS mediators correlate with measures of microvascular dysregulation and with organ failure.
\end{abstract}

\section{Introduction}

Sepsis is an inflammatory response to infection, and multiple organ failure contributes to the mortality of afflicted patients. Early restoration of systemic oxygen delivery aids in the resuscitation of patients with septic shock, but in contrast to other forms of shock, microvascular perturbations persist despite optimized global hemodynamics [1]. Because a disturbed microvasculature results in diminished nutrient extraction [2], clinicians now search for therapeutic goals of microvascular resuscitation in severe sepsis [3].

Direct imaging of the sublingual microcirculations of septic humans reveals decreased capillary density and

\footnotetext{
* Correspondence: kevin-doerschug@uiowa.edu

'Department of Internal Medicine, University of lowa Carver College of Medicine, 200 Hawkins Drive, lowa City, lowa, 52242, USA
}

heterogeneous flow patterns compared to controls [4]. Sepsis disrupts endothelial signaling and diminishes response to local vasodilators [5], suggesting that heterogeneous flow patterns may be due to abnormal vessel regulation. Indeed, hyperemic responses to transient ischemia are impaired in the septic human microvasculature [6-8], and the degree of impairment is associated with the degree of organ failure [9].

Angiotensin II (Ang II) is a potent vasoconstrictor and diminishes vasodilator responses in arteries [10]. In addition to direct effects on vascular tone, Ang II affects multiple aspects of microvascular function through promotion of leukostasis [11], induction of capillary permeability [12], and depletion of glutathione [13]. The renin-angiotensin system (RAS) is activated in sepsis, and recent studies implicate Ang II in the pathogenesis of acute lung injury in animal models [14]. Although

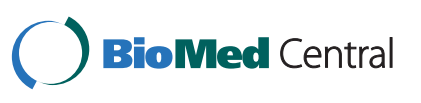

(c) 2010 Doerschug et al.; licensee BioMed Central Ltd. This is an open access article distributed under the terms of the Creative Commons Attribution License (http://creativecommons.org/licenses/by/2.0), which permits unrestricted use, distribution, and reproduction in any medium, provided the original work is properly cited. 
RAS mediators are present in the blood and microcirculatory structures during sepsis, the relationships between RAS and microvascular function during clinical sepsis have not been investigated. We hypothesize that RAS activation is associated with impaired microvascular regulation and organ dysfunction in patients with sepsis. To test this hypothesis, we studied a prospective cohort of human subjects with severe sepsis. Circulating mediators of RAS were measured and compared to both microvascular responses during reactive hyperemia as well as to organ dysfunction.

\section{Materials and methods Study design}

We studied 30 consecutive patients in our Medical Intensive Care Unit who fulfilled enrollment criteria, including 1) severe sepsis, defined as signs of systemic inflammation in the setting of probable or confirmed infection, as originally described in a consensus statement [15] and a more recently refined consensus [16], and confirmed by attending critical care physician evaluation; 2) organ failure for no more than 24 hours; 3 ) signed informed consent, including from surrogate decision-makers. Patients were excluded for the following reasons: 1) recent chemotherapy; 2) recent steroid or immunosuppressive agents; 3 ) severe peripheral vascular disease, dialysis fistulas, or mastectomies that would preclude safe forearm occlusion; 4) "Do Not Resuscitate" order at time of enrollment. Ten of these 30 subjects were included in a previous report that validated the NIRS methodology [9]. In addition to sepsis subjects, we studied 10 healthy volunteers that did not take any medications. This study was performed in a manner compliant with the Helsinki Declaration, and approved by the University of Iowa Institutional Review Board.

Sepsis subjects were studied 24 hours after the clinical recognition of organ dysfunction, corresponding to a time of clinical significance $[17,18]$, and when the prognostic value of microvascular function has been well studied $[4,9,19]$. Twelve of these septic subjects were enrolled early such that an initial study could also be performed eight hours after the recognition of organ dysfunction; this subset of subjects was evaluated following the phase of Early Goal Directed Therapy, after which vascular resuscitation may be less effective [20]. All resuscitation goals and methods were left to the ICU team. Clinical data were collected prospectively. Organ failure was assessed using the Sequential Organ Failure Assessment (SOFA) scoring system, using the 24 hour worstcase score for each organ system as originally validated [18]. Vasoconstrictor use was classified according to criteria for the SOFA cardiovascular component. Accordingly, low dose vasoconstrictors include Dopamine $>5$ $\mathrm{mcg} / \mathrm{kg} / \mathrm{min}$ or Norepinephrine $\leq 0.1 \mathrm{mcg} / \mathrm{kg} / \mathrm{min}$, and high-dose vasoconstrictors include Dopamine $>15 \mathrm{mcg} /$ $\mathrm{kg} / \mathrm{min}$ or Norepinephrine $>0.1 \mathrm{mcg} / \mathrm{kg} / \mathrm{min}$. Since the validation of SOFA scores, arginine vasopressin infusions have been shown to decrease the need for additional vasopressors and now are used commonly. Because vasopressin effects on blood pressure are considered similar to those of norepinephrine [21], subjects on vasopressin as a single vasoactive agent were given a cardiovascular component score of 3 , while those on vasopressin plus additional agents were given a score of 4 .

\section{Measurements of RAS activity}

Blood was collected using ethylenediaminetetraacetate (EDTA)-filled vacuum phlebotomy tubes. Samples were immediately placed on ice and plasma was separated and frozen to $-80^{\circ} \mathrm{C}$ within 30 minutes of blood draw. The rate of generation of angiotensin in ex-vivo plasma, or plasma renin activity (PRA), was assayed using a commercial radioimmune assay (RIA) kit (DiaSorin, Stillwater, MN, USA). One tube was prechilled and prefilled with the converting enzyme inhibitor bestatin to prevent ex-vivo generation of Ang II. Subsequently, the plasma concentration of Ang II was measured using a commercial RIA kit (ALPCO, Salem, NH, USA).

\section{Microvascular responses to reactive hyperemia}

We utilized near infrared spectroscopy (NIRS) to monitor microvascular responses to reactive hyperemia in thenar skeletal muscle [9]. NIRS detects the oxygen saturation of hemoglobin specifically in skeletal muscle tissue microvasculature $\left(\mathrm{S}_{\mathrm{t}} \mathrm{O}_{2}\right)$ with little influence from myoglobin or from blood flow to skin or other tissues $[22,23]$. The Inspectra 325 Tissue Spectrometer (Hutchinson Technology, Hutchinson, MN, USA) utilizes 15 $\mathrm{mm}$ spacing between emission and detection points, and provides tissue attenuation measurements at four discreet wavelengths $(680,720,760$, and $800 \mathrm{~nm})$ [24]. Prior to NIRS testing, patients inhaled $100 \%$ oxygen to maximize $\mathrm{S}_{\mathrm{p}} \mathrm{O}_{2}$. Using techniques previously validated [9], forearm stagnant ischemia was maintained via a vascular cuff inflated to $250 \mathrm{~mm} \mathrm{Hg}$ for five minutes, then the cuff was deflated rapidly. We defined the reoxygenation rate as the rate of increase of $\mathrm{S}_{\mathrm{t}} \mathrm{O}_{2}$ during the immediate 14 seconds after the release of ischemia. This technique represents the summative rate of all arterial influx to the tissue microvasculature and hence the microvascular response to reactive hyperemia [9]. To determine the reproducibility of our measurements, four additional normal control subjects underwent repeated ischemia/reoxygenation testing with 10 minutes rest between ischemic periods.

Microvascular responses were evaluated immediately following phlebotomy for RAS mediators. The family of one septic subject refused stagnant ischemia after the 
enrollment process due to deterioration of clinical status; the previously collected clinical and plasma data are included in the analysis.

\section{Statistical analysis}

Clinical, NIRS, and plasma data were analyzed with GraphPad Prism software v4.0 (San Diego, CA, USA). Candidate groups for comparison were assessed with a normality test, and Student's t-test was utilized if appropriate. Medians of two groups with non-Gaussian distributions were compared with Mann-Whitney tests, whereas medians of three groups with non-Gaussian distributions were compared with the Kruskal-Wallis test; post-hoc analyses of significant differences $(\alpha<$ 0.05) were investigated with Dunn's Multiple Comparison Test. A Pearson correlation coefficient was calculated to compare linear relationships between two continuous variables with Gaussian distributions; a Spearman coefficient was calculated when non-Gaussian distributions were noted. Individual statistical tests are specifically stated in each figure legend.

\section{Results}

Thirty subjects fulfilled our enrollment criteria, including 12 subjects enrolled early such that an eight-hour study could also be performed. Clinical data are summarized in Table 1. Our subjects demonstrated a broad age range and a slight male predominance. Pneumonia was the most common infection leading to sepsis. Vasoconstrictor use was common, as was mechanical ventilation, while nearly half of our patients developed extensive organ dysfunction culminating in a SOFA score of 10 or greater (a predictor of $50 \%$ mortality). Patients with severe sepsis were resuscitated according to clinician preference, including a mean total fluid intake over eight liters in the first 24 hours of ICU care. The mean value of mean arterial pressures in our subjects was $69 \mathrm{~mm} \mathrm{Hg}$ (SD $10.4 \mathrm{~mm} \mathrm{Hg}$ ). Although no subject had chronic renal failure requiring renal replacement therapy prior to enrollment, the median serum creatinine was $1.7 \mathrm{mg} / \mathrm{dL}$. Overall, our subjects experienced $67 \%$ survival. These features represent a typical severe sepsis population at high risk of death.

Median values for PRA $(7.4 \mathrm{ng} / \mathrm{mL} / \mathrm{h}$, range 0.1 to $49.7 \mathrm{ng} / \mathrm{mL} / \mathrm{h})$ and Ang II $(29.8 \mathrm{pg} / \mathrm{mL}$, range 3.1 to $242.8 \mathrm{pg} / \mathrm{mL}$ ) were elevated at 24 hours, despite resuscitation to clinical endpoints of preload and mean arterial pressure (see Figure 1). There was no relationship between serum creatinine and either measure of RAS activation. However, PRA correlated with total SOFA score (Spearman $\mathrm{r}=0.44, P=0.01$ ). Ang II did not correlate with SOFA scores at 24 hours. We compared values of PRA and Ang II to assess consistency within an intact biologic system and found a strong correlation
Table 1 Clinical data of severe sepsis subjects

\begin{tabular}{|c|c|c|}
\hline & Mean & Range \\
\hline Age (years) & 56 & 31 to 85 \\
\hline Mean arterial pressure $(\mathrm{mm} \mathrm{Hg})$ & 69 & 48 to 91 \\
\hline Heart rate (beats/min) & 91 & 51 to 124 \\
\hline $\mathrm{S}_{\mathrm{p}} \mathrm{O}_{2}(\%)$ & 97 & 90 to 100 \\
\hline Hemoglobin, $(\mathrm{g} / \mathrm{dL})$ during NIRS & 11 & 8.6 to 22.4 \\
\hline Blood Lactate*, maximum value & 3.7 & 0.7 to 10.3 \\
\hline Serum Creatinine, (mg/dL) & 2 & 0.5 to 7.6 \\
\hline \multirow[t]{2}{*}{ SOFA Score } & 10 & 1 to 19 \\
\hline & $n$ & $\%$ \\
\hline Total enrolled & 30 & 100 \\
\hline Male gender & 17 & 57 \\
\hline Severe organ failuret & 14 & 47 \\
\hline Vasoconstrictor use $\mathrm{e}^{\ddagger}$ & 21 & 70 \\
\hline Mechanical Ventilation & 21 & 70 \\
\hline Survive, in-hospital & 20 & 67 \\
\hline \multicolumn{3}{|l|}{ Source of Infection } \\
\hline Pneumonia & 15 & 50 \\
\hline Genitourinary & 5 & 17 \\
\hline Abdominal & 5 & 17 \\
\hline Endovascular ${ }^{\neq \neq}$ & 4 & 13 \\
\hline Multiple foci & 1 & 3 \\
\hline
\end{tabular}

$\mathrm{S}_{\mathrm{p}} \mathrm{O}_{2}$, arterial oxygen saturation by pulse oximetry; SOFA, sequential organ failure assessment. ${ }^{*} n=25$ subjects. ${ }^{\dagger}$ Severe organ failure defined as SOFA $\geq$ 10. ${ }^{\ddagger}$ Vasoconstrictor use includes dopamine $>5 \mathrm{mcg} / \mathrm{kg} / \mathrm{min}$ or any dose of norepinephrine or vasopressin. ${ }^{\neq \neq}$Endovascular denotes bacteremia without detectable extravascular source of infection.

between these mediators (Spearman $\mathrm{r}=0.75 ; P<$ 0.0001 ; see Figure 2). Mean arterial pressure did not correlate with PRA ( $\mathrm{r}=-0.31, P=0.10)$ and only weakly correlated with Ang II $(\mathrm{r}=-0.43, P=0.02)$. Since many of our subjects were being treated with vasoactive drugs, and because catecholamines may stimulate renin release, we sought interactions between such therapy and circulating RAS mediators. Concentrations of the potent vasoconstrictor Ang II were similar in subjects receiving exogenous vasoconstrictor infusions and those not receiving these drugs (mean $54.9 \mathrm{pg} / \mathrm{mL}$, SD 56.4 vs $37.5 \mathrm{pg} / \mathrm{mL}$, SD 41.6; normality test $P>0.1$ for each group, Student t-test $P=0.4$ ).

At the same time that plasma was sampled for PRA and Ang II, we assessed the microvascular response to reactive hyperemia using NIRS. The reoxygenation rate following ischemia was impaired in septic compared to control subjects (mean 3.0\% per sec (SD 1.6) vs. $4.8 \%$ per sec (SD1.1); t-test $P=0.003)$. The coefficient of variability of the reoxygenation rate in normal control subjects was $23 \%$, similar to previous reports [25]. The reoxygenation rate correlated negatively with the degree of organ dysfunction in septic subjects (Pearson $\mathrm{r}=$ $-0.50, P=0.007$; see Figure 3 ), confirming our prior findings [9]. The reoxygenation rate was lower in those 
A

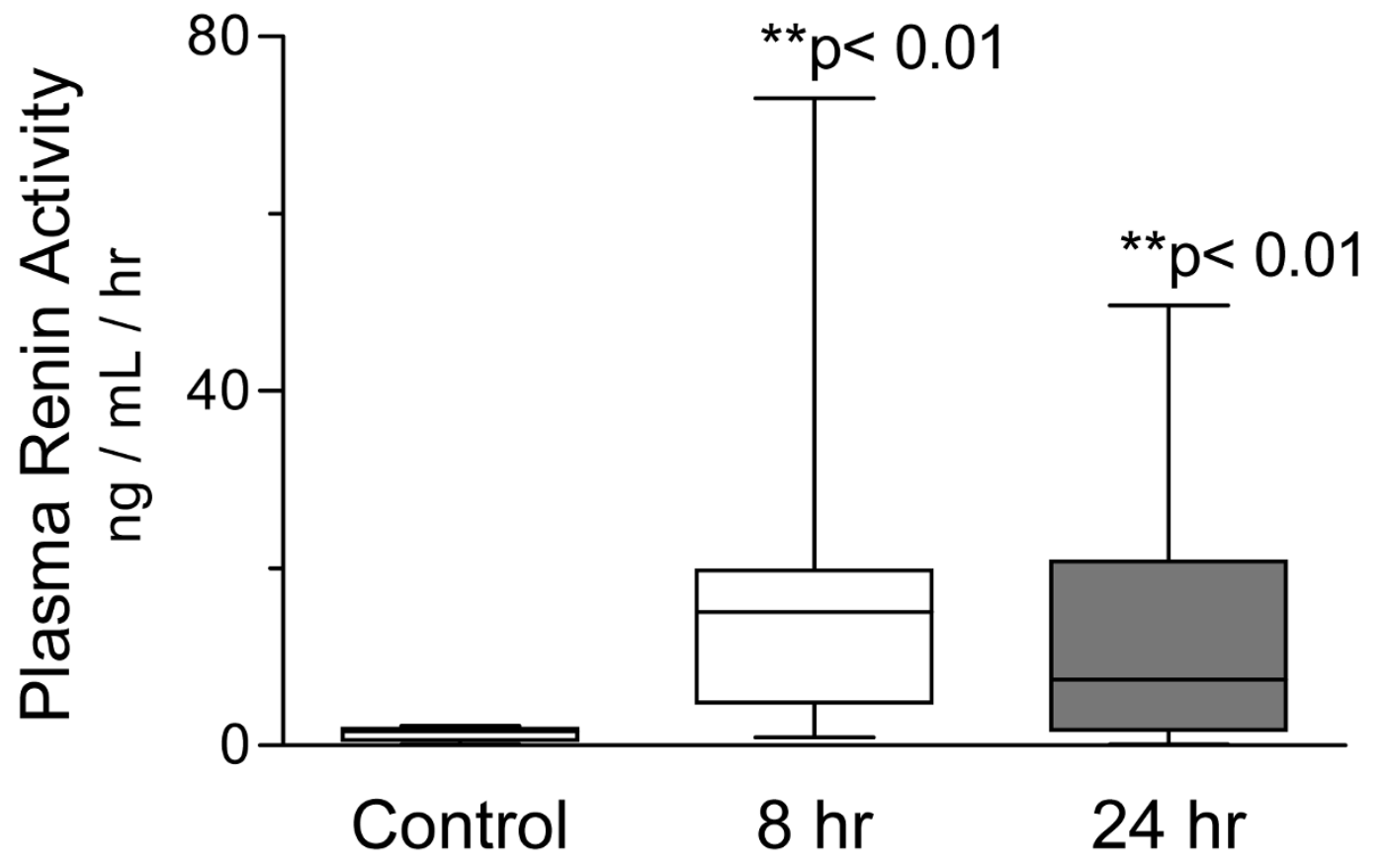

B

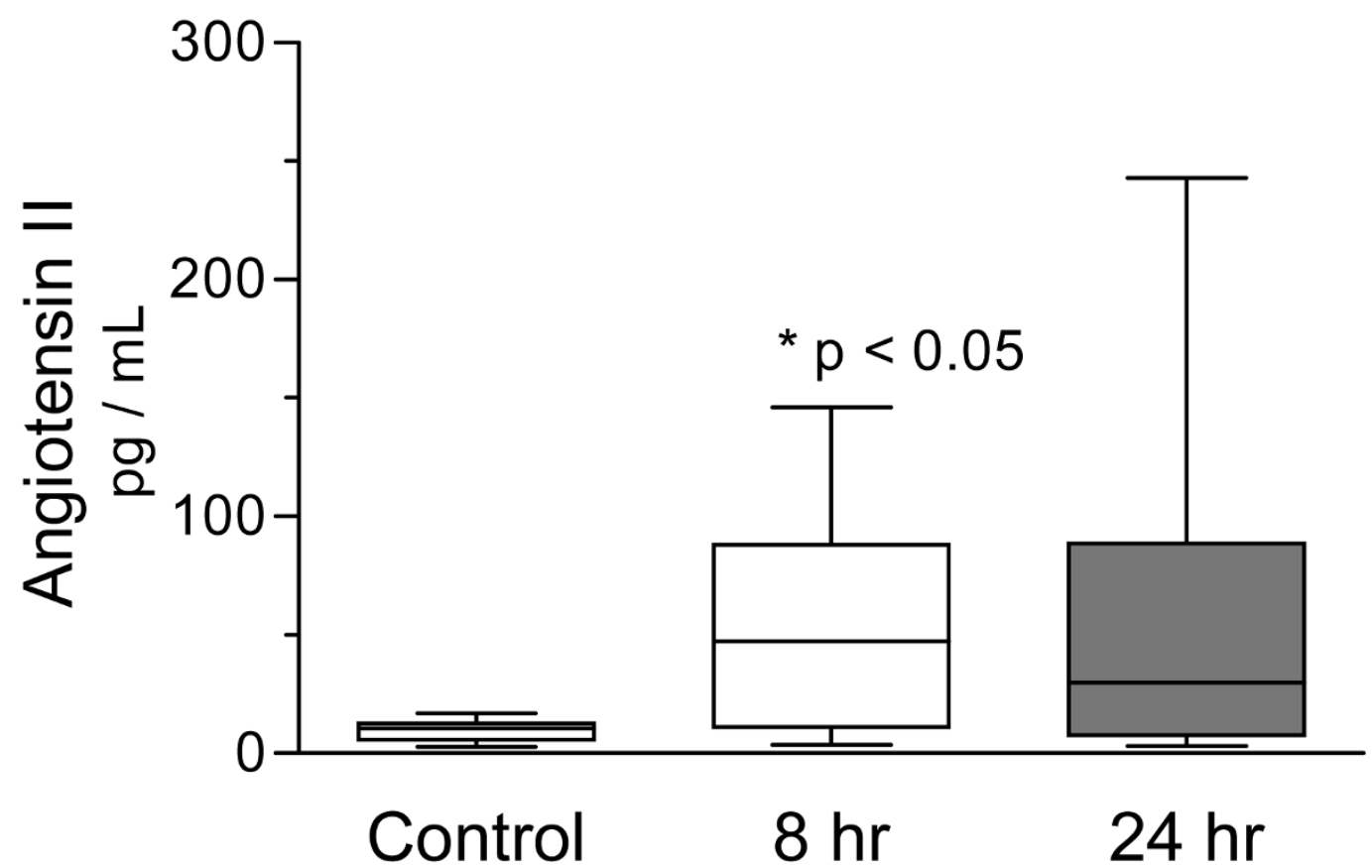

Figure 1 Circulating RAS mediators are prevalent in the septic circulation. Plasma renin activity (Panel $\mathbf{A}$ ) and the plasma concentration of angiotensin II (Panel B) were assessed in control $(n=10)$ and septic subjects. At eight hours following the recognition of organ dysfunction, both PRA and Ang II were elevated in septic subjects $(n=12)$. Despite resuscitation to clinical endpoints, median values for PRA (7.4 ng/mL/hr, range 0.1 to $49.7 \mathrm{ng} / \mathrm{mL} / \mathrm{hr}$ ) and Ang $\|(29.8 \mathrm{pg} / \mathrm{mL}$, range 3.1 to $242.8 \mathrm{pg} / \mathrm{mL})$ remained elevated at 24 hours ( $\mathrm{n}=30)$. Data depict median, interquartile range, and range for each column. ${ }^{*} P<0.05,{ }^{* *} P<0.01$ compared to control, Kruskal-Wallis test, and Dunn's Multiple Comparison post-hoc test. 


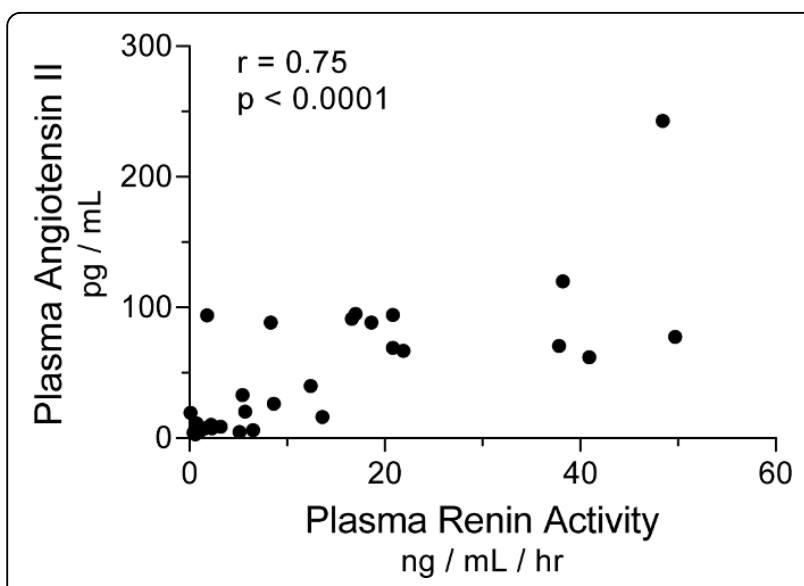

Figure 2 Plasma renin activity correlates with plasma concentration of angiotensin II in septic patients. PRA and Ang II were measured 24 hours after the recognition of organ dysfunction in 30 septic patients. Correlation analysis showed a significant relationship between these factors (Spearman $r=0.75$; $P$ $<0.0001)$

subjects receiving exogenous vasoconstrictors (mean $2.6 \%$ per sec (SD 1.6)) than in those not on vasoconstrictors (mean $4.0 \%$ per sec (SD 1.3); t-test $P=0.03$ ). This did not appear to depend on drug dose as reoxygenation rates for those on high dose vasoconstrictors (2.6\% per sec, SD 1.8) were similar to those on lower doses $(2.7 \%$ per sec, SD 0.78 ; t-test $P=0.88)$. Similarly, reoxygenation rates were lower in 20 septic subjects receiving continuous sedation during mechanical ventilation $(2.45 \%$ per sec, SD 1.21) compared to septic

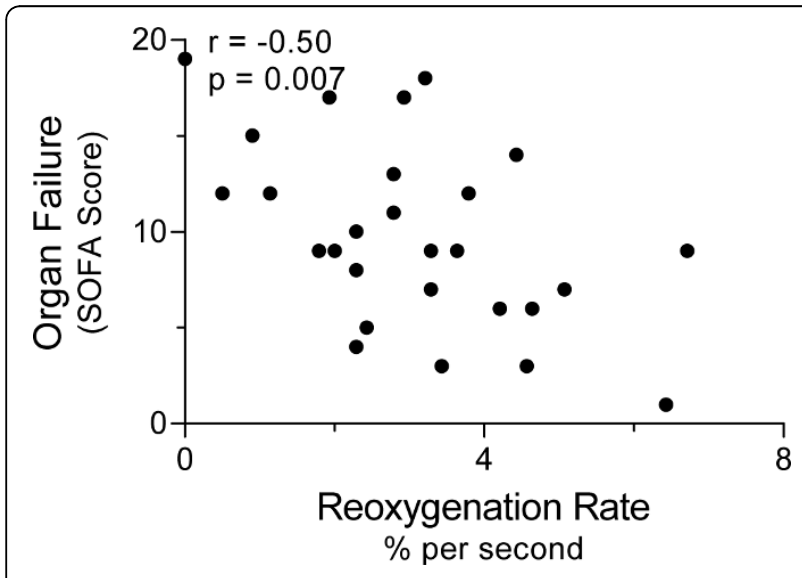

Figure 3 Microvascular responses to reactive hyperemia correlate inversely with organ dysfunction in severe sepsis. The microvascular response to reactive hyperemia was assessed by NIRS measures of thenar reoxygenation rates following induced forearm ischemia in 28 subjects. Correlation analysis showed a significant inverse relationship between microvascular reoxygenation rates and the degree of organ failure as assessed with the Sequential Organ Failure Assessment (SOFA) score (Pearson $r=-0.50, P=0.007$ ). subjects that were not ventilated $(4.27 \%$ per sec, SD 1.68 ; t-test $P=0.03)$. Within the subset of ventilated septic subjects, reoxygenation rates still correlated with total SOFA score $(\mathrm{r}=-0.48 ; P=0.037)$. A novel finding is that these microvascular responses correlated with RAS mediators in septic subjects. We found negative correlations between reoxygenation rates and both PRA (Spearman $\mathrm{r}=-0.52, P=0.005$ ) and Ang II (Spearman $\mathrm{r}=-0.41, P=0.03$, see Figure 4 ).

In the subset of 12 subjects studied eight hours following the recognition of sepsis-induced organ dysfunction, our findings were quite similar. Three subjects $(25 \%)$ studied at this early timepoint ultimately did not

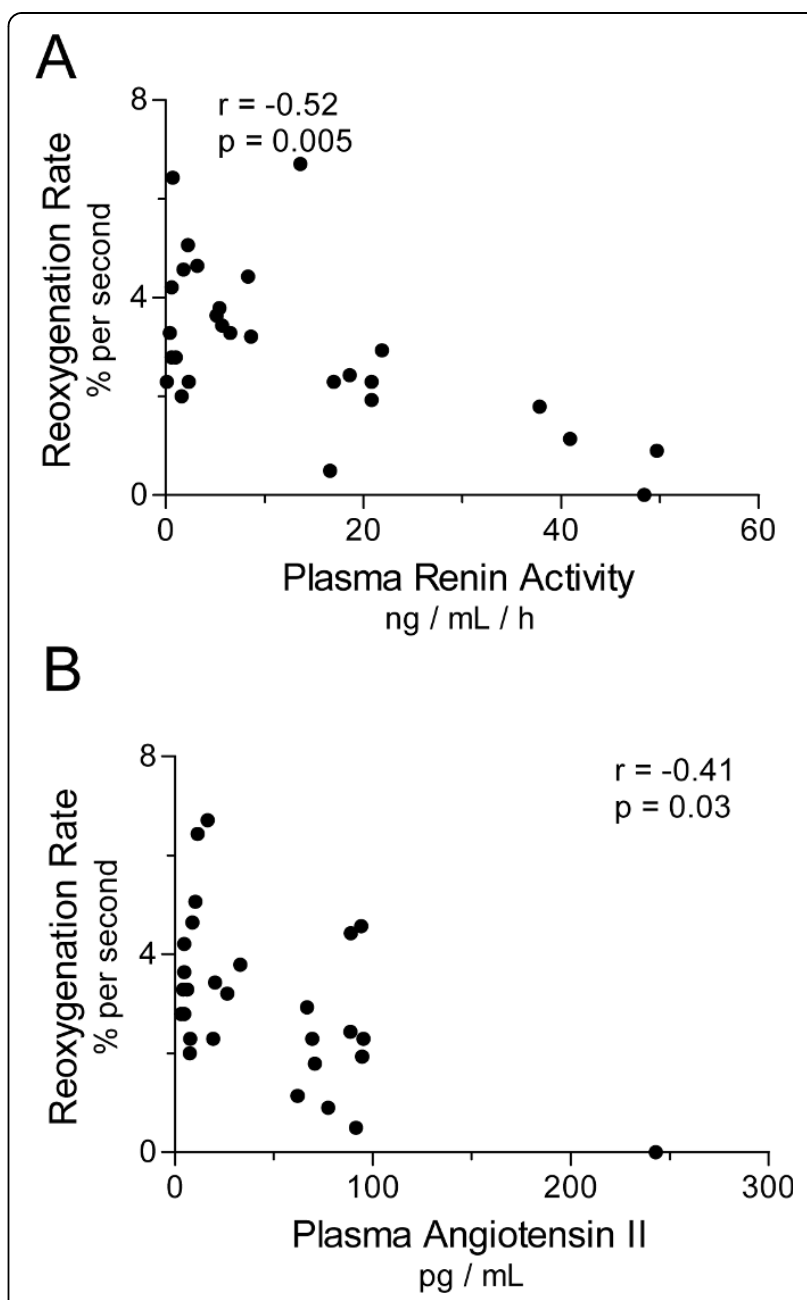

Figure 4 Circulating RAS mediators correlate inversely with the microvascular responses to reactive hyperemia. Circulating RAS mediators were assessed by radioimmune assay of plasma from septic subjects 24 hours following the clinical onset of organ dysfunction. Correlation analysis showed both plasma renin activity (Panel $\mathbf{A}$; Spearman $r=-0.52, P=0.005$ ) and plasma angiotensin II concentration (Panel B; Spearman $r=-0.41, P=0.03$ ) had significant inverse linear relationships with thenar reoxygenation rates, or microvascular responses to reactive hyperemia. 


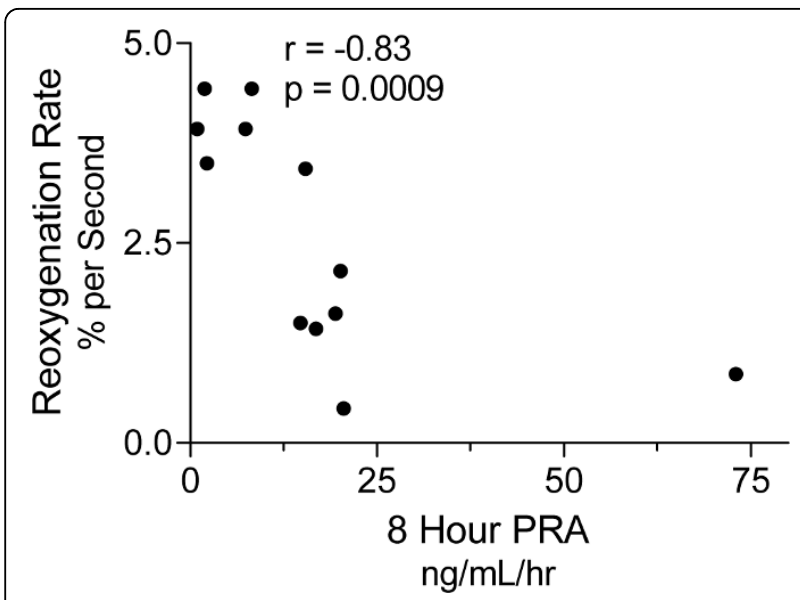

Figure 5 Early RAS activation correlates with microvascular dysfunction. Plasma renin activity was assessed by radioimmune assay of plasma from a subset of 12 subjects studied eight hours following the recognition of organ failure. Correlation analysis showed PRA had a significant inverse relationship (Spearman $r=$ $-0.83, P=0.0009$ ) with microvascular reoxygenation rates.

survive hospitalization. The median PRA was significantly elevated in early septic subjects $(15.1 \mathrm{ng} / \mathrm{mL} / \mathrm{h}$, range 0.9 to $73 \mathrm{ng} / \mathrm{mL} / \mathrm{h}$ ) compared to controls $(1.5 \mathrm{ng} /$ $\mathrm{mL} / \mathrm{h}$, range 0.1 to $2.2 \mathrm{ng} / \mathrm{mL} / \mathrm{h}$; see Figure 1, Panel A). Circulating Ang II was also increased in sepsis subjects (median $47.2 \mathrm{pg} / \mathrm{mL}$, range 3.7 to $146 \mathrm{pg} / \mathrm{mL}$ ) at this early timepoint (control median $10.6 \mathrm{pg} / \mathrm{mL}$, range 2.8 to $17 \mathrm{pg} / \mathrm{mL}$; see Figure 1, Panel B). Early PRA correlated negatively with microvascular reoxygenation rates measured at the same timepoint (Spearman $\mathrm{r}=-0.83$, $P=0.0009$; see Figure 5). Strikingly, the plasma concentration of Ang II early in sepsis correlated with the extent of organ dysfunction realized during the first day of ICU care (Spearman $r=0.66, P=0.019$; see Figure 6). In parallel, early Ang II concentrations in those that ultimately survived hospitalization (mean $36.0 \mathrm{pg} / \mathrm{mL}$, SD $36 \mathrm{pg} / \mathrm{mL}$ ) were lower than those in subjects that died (mean $105.8 \mathrm{pg} / \mathrm{mL}$, SD $36.4 \mathrm{pg} / \mathrm{mL}$; normality test $P>.1$; Student t-test $P=0.016$ ).

\section{Discussion}

We found that circulating mediators of RAS are prevalent in clinically severe sepsis. As such we have confirmed prior studies $[26,27]$ and extended the evaluation of RAS mediators to two relevant timepoints during resuscitation. Additionally, we have demonstrated relationships between RAS mediators and impaired physiology within human septic subjects.

Our previous work documented that arteriolar influx to skeletal muscle tissue was most impaired in septic patients with profound vital organ failure [9]. Using similar techniques, others have found this measure to be most impaired in septic patients who do not survive [19]. The negative linear relationship between microvascular regulation and organ failure in our current study substantiates the reliability and relevance of this physiologic measurement.

Several therapeutic interventions in the care of septic subjects can potentially alter vascular responses. Continuous infusions of propofol, benzodiazepines, and opiates were used in our subjects that required mechanical ventilation, and are known to impair vasodilatory responses. That reoxygenation rates correlated with overall severity of illness score even within this subgroup suggests that sedative infusions themselves are not the major cause of impaired responses in our subjects.

It is interesting that responses to reactive hyperemia were most impaired in our subjects receiving exogenous vasoconstrictors (with a modest test of significance and with no evidence of a dose-response), while previously we found no relationship between vasoconstrictor use and diminished responses in septic subjects. Other groups have similarly described only a limited relationship between exogenous vasoconstrictors and diminished microvascular responses in septic patients [19]. When norepinephrine infusions are titrated to escalating arterial pressure targets in septic patients, some subjects have an ideal resuscitation point above or below which microvascular perfusion is impaired [28]. This leaves open the possibility that some of our observed microvascular dysfunction may have been due to inadequate resuscitation. However, this occurs in a minority of septic subjects whereas microvascular flow is generally not altered when norepinephrine is titrated to mean arterial pressures ranging from 60 to $90 \mathrm{~mm} \mathrm{Hg}$ [29]. Catecholamines alter vasodilatory responses, but any analysis of vasomotor responses must consider that circulating endogenous vasoconstrictors are elevated in sepsis and likely affect hyperemic responses even in patients that don't receive vasoconstrictor infusions. The limited relationship between vasoconstrictor infusions and hyperemic responses in our studies suggest that exogenous catecholamines do not play a large role (compared to endogenous factors) in dampening hyperemic responses. Because Ang II was equally elevated in patients who did or did not receive exogenous vasoconstrictors, we are urged to investigate relationships between circulating RAS mediators and microvascular function in sepsis.

We considered that RAS activation might simply reflect glomerular hypoperfusion due to hypovolemia, hypotension, or insufficient resuscitation. The clinical use of vasopressors, mechanical ventilation, and fluid resuscitation in our subjects was consistent with aggressive resuscitative efforts during the first day of sepsis, although we did not standardize resuscitation to measures of cardiac output, pulmonary artery occlusion (wedge) pressure, or pulse 

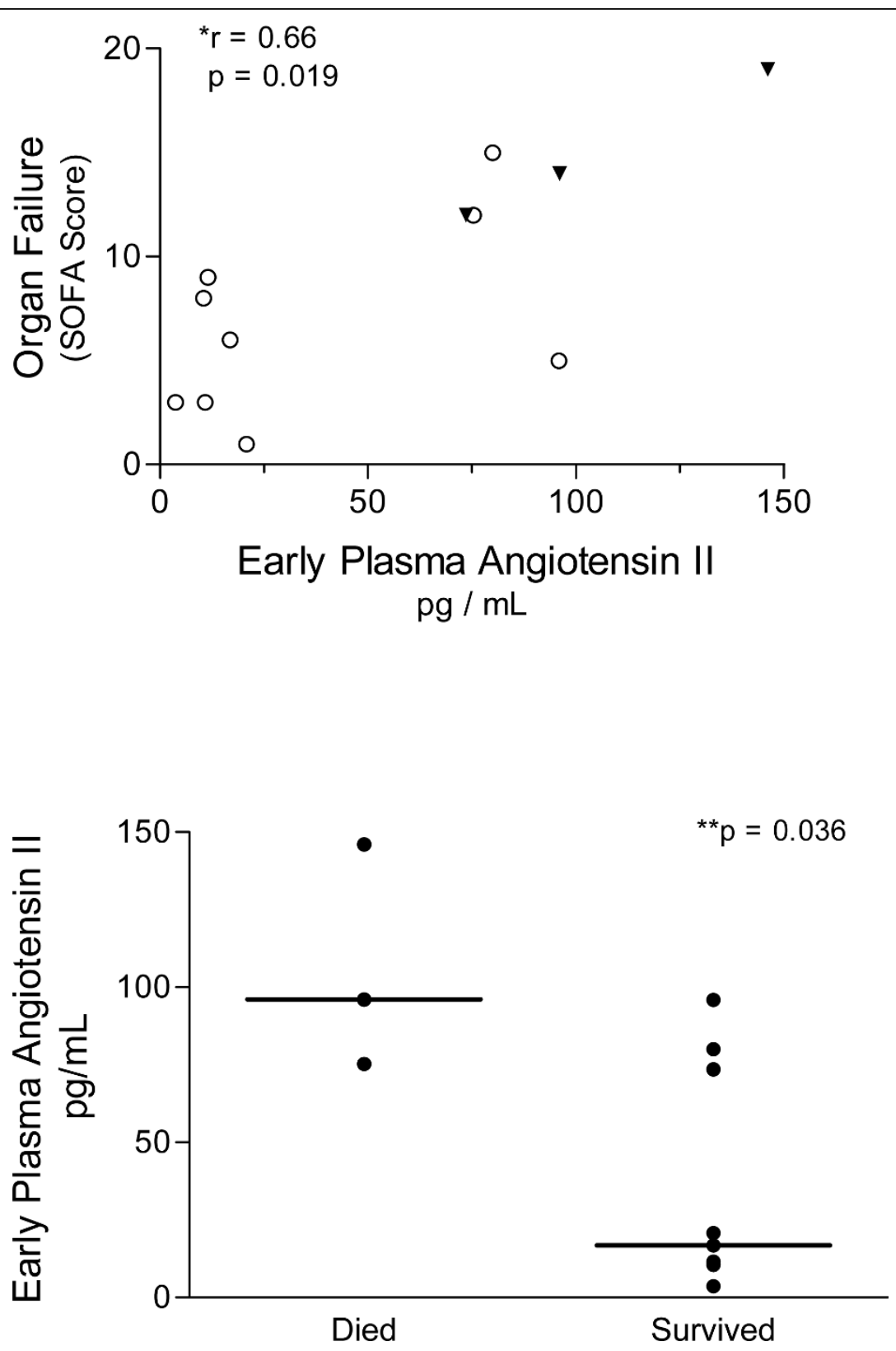

Figure 6 Early plasma angiotensin II concentration correlates with organ failure in severe sepsis. Plasma angiotensin II concentration was measured eight hours after the recognition of organ failure in 12 septic subjects. Panel $\mathbf{A}$ : Correlation analysis of these 12 subjects showed a significant relationship (Spearman $r=0.66 ;{ }^{*} P=0.019$ ) between Ang II and the extent of organ failure realized during the first day of ICU care as determined by the Sequential Organ Failure Assessment (SOFA) Score. Data shown includes subjects that died (black triangles) or survived hospitalization (open circles). Panel B: Early Ang II concentrations in those that ultimately survived hospitalization (mean 36.0 pg/mL, SD 36 pg/ $\mathrm{mL}$ ) were lower than those in subjects that died (mean $105.8 \mathrm{pg} / \mathrm{mL}, \mathrm{SD} 36.4 \mathrm{pg} / \mathrm{mL}$; ${ }^{* *}$ normality test $P>.1$; Student t-test $P=0.016$ ).

pressure variation in accord with uncertainties regarding what these goals should be [30-32]. Similarly, preexisting hypertension, diabetes, and coronary disease are associated with increased RAS activity, and no doubt are co-morbid conditions in clinical sepsis. We note that the levels of PRA and Ang II measured in our septic subjects are elevated nearly two-fold compared to outpatients with risk factors for vascular disease [33,34], arguing that the acute septic state contributes to RAS activation. Although we did identify a relationship between arterial hypotension and circulating Ang II after the first day of severe sepsis, the modest statistical significance and lack of a similar relationship between hypotension and PRA (a biologic precursor to Ang II) temper our enthusiasm to declare arterial pressure a dominant factor leading to persistent RAS activation during sepsis. 
Our most novel finding is the association of circulating mediators of RAS with impaired hyperemic responses to ischemia during sepsis. This association raises the possibility that sepsis stimulates RAS, which contributes to microvascular perfusion heterogeneity (manifested as impaired response to local ischemia), and that perfusion heterogeneity contributes to organ failure. We cautiously note that our studies do not define a causal role of RAS in the pathogenesis of septic microvascular dysfunction, and RAS activation may be unrelated or even compensatory for microvascular dysfunction. However, findings of increased small vessel density and decreased heterogeneity following vasodilator administration to septic subjects $[35,36]$ suggest that an enhanced vasoconstrictor tone contributes to perturbations of the microvasculature. Thus our findings suggest that RAS contributes to the enhanced microvascular tone in human sepsis.

Ang II inhibits endothelium-dependent relaxation of resistance arteries [37] and thus modulates the response to ischemia. Antagonism of the angiotensin type 1 receptor increases blood flow to ischemic mesenteries [38] and attenuates mucosal permeability and bacterial translocation [39] in animal models of shock. In addition to direct effects on vascular tone, Ang II induces adhesion marker expression on both leukocytes and endothelial cells $[40,41]$ and thus may propagate the hemostatic and inflammatory interactions implicated in microvascular perturbations and organ failure during sepsis. We note that early Ang II correlates with the extent of organ failure achieved during the first day, but Ang II values later in the course of sepsis do not correlate with SOFA scores. The explanation for this discrepancy is not clear. It is possible that Ang II is an early mediator in a cascade of events that results in organ failure over the first day, and as such the late concentration of Ang II is less relevant to organ failure.

Circulating precursors to Ang II also have biologic importance. It is worth noting that PRA also correlated with impaired hyperemic responses as well as SOFA scores in our studies. Inhibition of angiotensin converting enzyme (ACE) with enalapril improves endotheliumdependent relaxation in endotoxemic animals [42]. ACE inhibition decreases endothelial-derived adhesion molecules and vasoconstrictors, improves gut perfusion, and reduces organ failure in critically ill patients [26,43]. Our studies provide evidence of associations between RAS and relevant microvascular perturbations in sepsis. Importantly, our studies provide an impetus to determine if pharmacologic RAS blockade can increase microvascular function and improve septic patient outcomes.

\section{Conclusions}

RAS mediators are present in the systemic circulation in human sepsis. Plasma renin activity and angiotensin
II concentrations correlate with impairments in microvascular dysfunction, organ failure, and mortality. These derangements appear early and persist through the first day of severe sepsis despite macrovascular resuscitation.

\section{Key messages}

- The renin-angiotension system (RAS) activation correlates with organ injury and mortality in clinical sepsis.

- Systemic RAS mediators persist in many septic patients despite macrovascular resuscitation.

- Microvascular responses to ischemia are impaired in clinical sepsis and correlate with vital organ function.

- Systemic RAS mediators correlate inversely with microvascular responses to ischemia.

- Future work can determine if RAS antagonism can improve microvascular function and vital organ function in clinical sepsis.

\section{Abbreviations}

ACE: Angiotensin converting enzyme; Ang II: plasma concentration of angiotensin II; EDTA: ethylenediaminetetraacetate; NIRS: near infrared spectroscopy; PRA: plasma renin activity; RAS: Renin-Angiotensin System; RIA: radioimmune assay; SOFA: Sequential Organ Failure Assessment score; $\mathrm{S}_{\mathrm{p}} \mathrm{O}_{2}$ : percent oxygen saturation of arterial hemoglobin: as measured with pulse oximetry; $\mathrm{S}_{t} \mathrm{O}_{2}$ : percent oxygen saturation of microvascular (tissue) hemoglobin: as measured with NIRS.

\section{Acknowledgements}

This work was supported by the American Heart Association (0660058ZKCD) and National Institutes of Health (K23HL071246-KCD, K08DK073519$A A$, and RR-59).

\section{Author details}

${ }^{1}$ Department of Internal Medicine, University of lowa Carver College of Medicine, 200 Hawkins Drive, lowa City, lowa, 52242, USA. ${ }^{2}$ Department of Internal Medicine, Dartmouth Medical School, One Medical Center Drive, Lebanon NH, 03756, USA.

\section{Authors' contributions}

KCD participated in subject recruitment, microvascular analysis, data analysis, and manuscript preparation. ASD participated in subject recruitment, microvascular analysis, and data analysis. GAS participated in manuscript preparation and editing. AA participated in data analysis and manuscript preparation.

\section{Competing interests}

The authors declare that they have no competing interests.

Received: 25 August 2009 Revised: 30 December 2009 Accepted: 22 February 2010 Published: 22 February 2010

\section{References}

1. Fang $X$, Tang W, Sun S, Huang L, Chang YT, Castillo C, Weil MH: Comparison of buccal microcirculation between septic and hemorrhagic shock. Crit Care Med 2006, 34:S447-S453.

2. Ellis CG, Bateman RM, Sharpe MD, Sibbald WJ, Gill R: Effect of a maldistribution of microvascular blood flow on capillary O(2) extraction in sepsis. Am J Physiol Heart Circ Physiol 2002, 282:H156-164.

3. Bateman RM, Walley KR: Microvascular resuscitation as a therapeutic goal in severe sepsis. Crit Care 2005, 9(Suppl 4):S27-32. 
4. Sakr Y, Dubois MJ, De Backer D, Creteur J, Vincent JL: Persistent microcirculatory alterations are associated with organ failure and death in patients with septic shock. Crit Care Med 2004, 32:1825-1831.

5. Tyml K, Yu J, McCormack DG: Capillary and arteriolar responses to local vasodilators are impaired in a rat model of sepsis. J Appl Physiol 1998, 84:837-844.

6. Astiz ME, Tilly E, Rackow ED, Weil MH: Peripheral vascular tone in sepsis. Chest 1991, 99:1072-1075

7. De Blasi RA, Palmisani S, Alampi D, Mercieri M, Romano R, Collini S, Pinto G Microvascular dysfunction and skeletal muscle oxygenation assessed by phase-modulation near-infrared spectroscopy in patients with septic shock. Intensive Care Med 2005, 31:1661-1668.

8. Skarda DE, Mulier KE, Myers DE, Taylor JH, Beilman GJ: Dynamic nearinfrared spectroscopy measurements in patients with severe sepsis. Shock 2007, 27:348-353.

9. Doerschug KC, Delsing AS, Schmidt GA, Haynes WG: Impairments in microvascular reactivity are related to organ failure in human sepsis. Am J Physiol Heart Circ Physiol 2007, 293:H1065-1071.

10. Abboud FM: Vascular responses to norepinephrine, angiotensin, vasopressin and serotonin. Fed Proc 1968, 27:1391-1395.

11. Alvarez A, Cerda-Nicolas M, Naim Abu Nabah Y, Mata M, Issekutz AC, Panes J, Lobb RR, Sanz MJ: Direct evidence of leukocyte adhesion in arterioles by angiotensin II. Blood 2004, 104:402-408.

12. Victorino GP, Newton CR, Curran B: Effect of angiotensin II on microvascular permeability. J Surg Res 2002, 104:77-81.

13. Bechara RI, Pelaez A, Palacio A, Joshi PC, Hart CM, Brown LA, Raynor R, Guidot DM: Angiotensin II mediates glutathione depletion, transforming growth factor-\{beta\}1 expression, and epithelial barrier dysfunction in the alcoholic rat lung. Am J Physiol Lung Cell Mol Physiol 2005, 289: L363-370.

14. Imai Y, Kuba K, Rao S, Huan Y, Guo F, Guan B, Yang P, Sarao R, Wada T, Leong-Poi H, Crackower MA, Fukamizu A, Hui CC, Hein L, Uhlig S, Slutsky AS, Jiang C, Penninger JM: Angiotensin-converting enzyme 2 protects from severe acute lung failure. Nature 2005, 436:112-116.

15. Bone RC, Balk RA, Cerra FB, Dellinger RP, Fein AM, Knaus WA, Schein RM, Sibbald WJ: Definitions for sepsis and organ failure and guidelines for the use of innovative therapies in sepsis. Chest 1992, 101:1644-1655.

16. Levy MM, Fink MP, Marshall JC, Abraham E, Angus D, Cook D, Cohen J, Opal SM, Vincent JL, Ramsay G: 2001 SCCM/ESICM/ACCP/ATS/SIS International Sepsis Definitions Conference. Crit Care Med 2003, 31:1250-1256

17. Ferreira FL, Bota DP, Bross A, Melot C, Vincent JL: Serial evaluation of the SOFA score to predict outcome in critically ill patients. Jama 2001, 286:1754-1758.

18. Vincent $J$, de Mendonca A, Cantraine F, Moreno R, Takala J, Suter PM, Sprung $\mathrm{CL}$, Colardyn F, Blecher S: Use of the SOFA score to assess the incidence of organ dysfunction/failure in intensive care units: results of a multicenter, prospective study. Crit Care Med 1998, 26:1793-1800.

19. Creteur J, Carollo T, Soldati G, Buchele G, De Backer D, Vincent JL: The prognostic value of muscle $\mathrm{StO}(2)$ in septic patients. Intensive Care Med 2007, 33:1549-56.

20. Rivers E, Nguyen B, Havstad S, Ressler J, Muzzin A, Knoblich B, Peterson E, Tomlanovich M: Early goal-directed therapy in the treatment of severe sepsis and septic shock. N Engl J Med 2001, 345:1368-1377.

21. Dellinger RP, Levy MM, Carlet JM, Bion J, Parker MM, Jaeschke R, Reinhart $K$, Angus DC, Brun-Buisson C, Beale R, Calandra T, Dhainaut JF, Gerlach H, Harvey M, Marini JJ, Marshall J, Ranieri M, Ramsay G, Sevransky J, Thompson BT, Townsend S, Vender JS, Zimmerman JL, Vincent JL: Surviving Sepsis Campaign: International guidelines for management of severe sepsis and septic shock: 2008. Crit Care Med 2008, 36:296-327.

22. Mancini DM, Bolinger L, Li H, Kendrick K, Chance B, Wilson JR: Validation of near-infrared spectroscopy in humans. J Appl Physiol 1994, 77:2740-2747.

23. Boushel R, Piantadosi CA: Near-infrared spectroscopy for monitoring muscle oxygenation. Acta Physiol Scand 2000, 168:615-622.

24. Myers DE, Anderson LD, Seifert RP, Ortner JP, Cooper CE, Beilman GJ, Mowlem JD: Noninvasive method for measuring local hemoglobin oxygen saturation in tissue using wide gap second derivative nearinfrared spectroscopy. J Biomed Opt 2005, 10:034017.

25. Gomez H, Mesquida J, Simon P, Kim H, Puyana J, Ince C, Pinsky M: Characterization of tissue oxygen saturation and the vascular occlusion test: influence of measurement sites, probe sizes and deflation thresholds. Critical Care 2009, 13:S3.

26. Boldt J, Papsdorf M, Kumle B, Piper S, Hempelmann G: Influence of angiotensin-converting enzyme inhibitor enalaprilat on endothelialderived substances in the critically ill. Crit Care Med 1998, 26:1663-1670.

27. Hilgenfeldt U, Kienapfel G, Kellermann W, Schott R, Schmidt M: Reninangiotensin system in sepsis. Clin Exp Hypertens A 1987, 9:1493-1504

28. Dubin A, Pozo MO, Casabella CA, Palizas F Jr, Murias G, Moseinco MC, Kanoore Edul VS, Palizas F, Estenssoro E, Ince C: Increasing arterial blood pressure with norepinephrine does not improve microcirculatory blood flow: a prospective study. Crit Care 2009, 13:R92.

29. Jhanji S, Stirling S, Patel N, Hinds CJ, Pearse RM: The effect of increasing doses of norepinephrine on tissue oxygenation and microvascular flow in patients with septic shock. Crit Care Med 2009, 37:1961-1966.

30. Heenen S, De Backer D, Vincent JL: How can the response to volume expansion in patients with spontaneous respiratory movements be predicted?. Crit Care 2006, 10:R102.

31. The National Heart $L$, and Blood Institute Acute Respiratory Distress Syndrome (ARDS) Clinical Trials Network: Pulmonary-artery versus central venous catheter to guide treatment of acute lung injury. $N$ Engl J Med 2006, 354:2213-2224.

32. Durairaj L, Schmidt GA: Fluid therapy in resuscitated sepsis: less is more. Chest 2008, 133:252-263.

33. Higashi Y, Sasaki S, Nakagawa K, Matsuura H, Kajiyama G, Oshima T: Effect of the angiotensin-converting enzyme inhibitor imidapril on reactive hyperemia in patients with essential hypertension: relationship between treatment periods and resistance artery endothelial function. J Am Coll Cardiol 2001, 37:863-870.

34. Murphey $\amalg$, Morrow JD, Sawathiparnich P, Williams GH, Vaughan DE, Brown NJ: Acute angiotensin II increases plasma F2-isoprostanes in saltreplete human hypertensives. Free Radic Biol Med 2003, 35:711-718.

35. De Backer D, Creteur J, Preiser JC, Dubois MJ, Vincent JL: Microvascular blood flow is altered in patients with sepsis. Am J Respir Crit Care Med 2002, 166:98-104.

36. Spronk PE, Ince C, Gardien MJ, Mathura KR, Oudemans-van Straaten HM, Zandstra DF: Nitroglycerin in septic shock after intravascular volume resuscitation. Lancet 2002, 360:1395-1396.

37. Itoh T, Kajikuri J, Tada T, Suzuki Y, Mabuchi Y: Angiotensin II-induced modulation of endothelium-dependent relaxation in rabbit mesenteric resistance arteries. J Physiol 2003, 548:893-906.

38. Oldner A, Wanecek M, Weitzberg E, Rundgren M, Alving K, Ullman J, Rudehill A: Angiotensin II receptor antagonism increases gut oxygen delivery but fails to improve intestinal mucosal acidosis in porcine endotoxin shock. Shock 1999, 11:127-135.

39. Tadros T, Traber DL, Heggers JP, Herndon DN: Angiotensin II inhibitor DuP753 attenuates burn- and endotoxin-induced gut ischemia, lipid peroxidation, mucosal permeability, and bacterial translocation. Ann Surg 2000, 231:566-576

40. Mateo T, Abu Nabah YN, Abu Taha M, Mata M, Cerda-Nicolas M, Proudfoot AE, Stahl RA, Issekutz AC, Cortijo J, Morcillo EJ, Jose PJ, Sanz MJ: Angiotensin II-induced mononuclear leukocyte interactions with arteriolar and venular endothelium are mediated by the release of different CC chemokines. J Immunol 2006, 176:5577-5586.

41. Pastore L, Tessitore A, Martinotti S, Toniato E, Alesse E, Bravi MC, Ferri C, Desideri G, Gulino A, Santucci A: Angiotensin II stimulates intercellular adhesion molecule-1 (ICAM-1) expression by human vascular endothelial cells and increases soluble ICAM-1 release in vivo. Circulation 1999, 100:1646-1652.

42. Lund DD, Brooks RM, Faraci FM, Heistad DD: Role of Angiotensin II in Endothelial Dysfunction Induced by Lipopolysaccharide in Mice. Am J Physiol Heart Circ Physiol 2007, 293:H3726-31.

43. Kincaid EH, Miller PR, Meredith JW, Chang MC: Enalaprilat improves gut perfusion in critically injured patients. Shock 1998, 9:79-83.

doi:10.1186/cc8887

Cite this article as: Doerschug et al:: Renin-angiotensin system activation correlates with microvascular dysfunction in a prospective cohort study of clinical sepsis. Critical Care 2010 14:R24. 